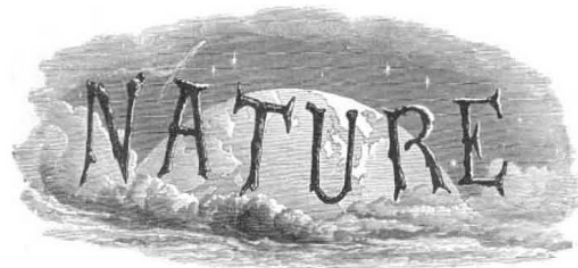

SATURDAY, AUGUST 6, 1932

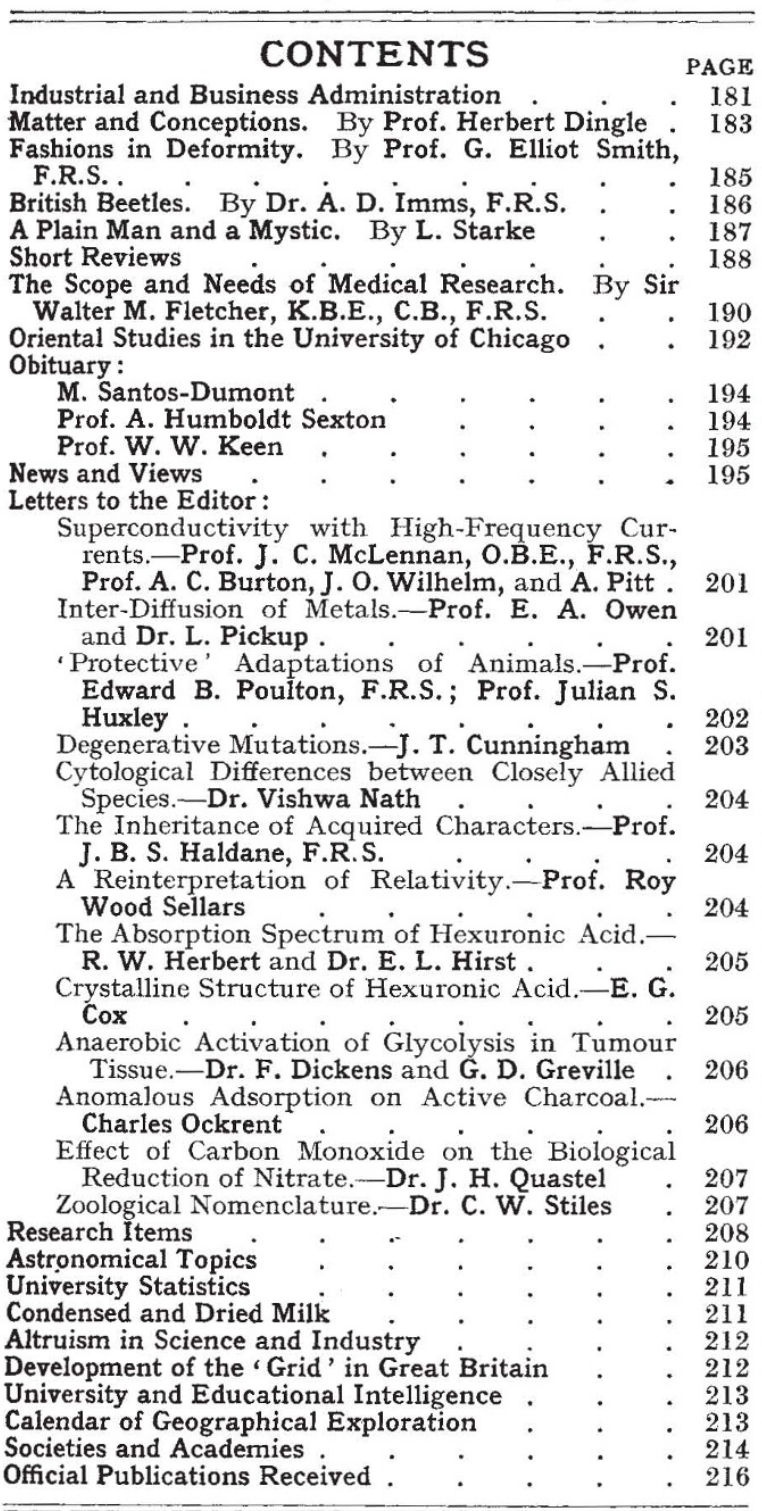

Editorial and Publishing Offices:

MACMILLAN \& CO., LTD.

ST. MARTIN'S STREET, LONDON, W.C. 2

Telephone Number: WHITEHALL 8831

Telegraphic Address: PHUSIS, LESQUARE, LONDON

Advertisements should be addressed to

T. G. Scott \& Son, Ltd., 63 Ludgate Hill, London, E. C. 4 Telephone Number: City 1266

\section{Industrial and Business Administration}

BEHIND the growing attention which is focused in these days on planning as an integral element in industrial revival or in national and international recovery, there is an increasing consciousness that the demands which are habitually made on leadership, whether of industry or of the State, are far more onerous than those of a few decades ago. It is not sufficient now for an industrial administrator to be competent to assess merely the internal and local factors of his industry. Whether they are financial, economic, political, or technical, he is compelled to extend his view to the national industry as a whole, and beyond that to an increasing extent to the industry as a world unit. Indifference to the international aspects of industry, like neglect of the technical and scientific factors, invites disaster, and this is as true of national administration as it is of industry. It would be difficult to name a single first-class problem with which modern political administrators are confronted which does not involve in its solution intricate and essential technical and scientific factors which cannot be appraised apart from scientific and technical knowledge.

As we have repeatedly urged in these columns, both industry and the State have in Great Britain suffered too much in the past from administrators whose deficiencies in scientific outlook and knowledge rendered them incapable of maintaining an adequate scientific staff, or of accepting an adequate and sustained programme of research as a fixed charge, comparable with insurance, depreciation, or obsolescence, and incorporating its results in industrial practice. In industry, however, this tendency is passing. The successful development of the newer industries such as those concerned with electrical equipment, automobiles and aviation, or the manufacture of synthetic products such as rayon, resins, etc., which has been primarily dependent upon research and the application of the results of scientific and technical investigation in commercial practice, has involved the organisation of close co-operation between administrators and controllers of policy and those responsible for research and other technical matters. The increasing authority and prestige of the technical expert in such industries is now extending to older industries, as may be seen in the appointment of an eminent man of science to direct and co-ordinate all research for the London Midland and Scottish Railway, an appointment carrying a status corresponding to that of the principal directing heads on the administrative side.

No. 3275 , VoL. 130] 
As a result of these developments in industry, there has thus been a considerable change from the control of industry by those whose chief qualifications are financial and commercial to control by boards of directors which collectively combine the knowledge of finance, general organisation, administrative problems, and the trend of scientific and technical developments requisite for wise and farseeing decisions on general policy. To this process the merging of industrial undertakings for the purposes of technical rationalisation has given a further impetus. Much of the wider and more urgent interest in management problems is derived from the rationalisation of industry. In fact, it may be said that the brief history of rationalisation in the world has already convincingly demonstrated that the success of a rationalisation policy is bound up inseparably with leadership competent to evaluate accurately all the relevant factors involved, whether scientific, technical, financial, or commercial. It is probably deficiencies in one or other of these respects, and consequent failure, that has led to suggestions that efficient administration of some of the largest international mergers is a task beyond human powers. Authoritative inquiry has, however, failed to reveal any evidence of such inherent limitations on human ability, and public opinion is gradually becoming sufficiently enlightened to perceive the true cause of such failures as lying in those who insist on discussing questions and policies involving technical or scientific considerations without the assistance of the appropriate experts.

Evidence of this change in the attitude of industry, and indeed of public opinion, can be found in the progress of such diverse institutions as the International Management Institute with its associated Management Research Groups, the Institute of Industrial Administration, which aims at establishing industrial administration as a recognised profession, as well as in the inclusion of a discussion on scientific management problems in the programme of Section F (Economics) at the centenary meeting of the British Association last year.

Among these, one of the most interesting experiments is the Department of Business Administration at the London School of Economics and Political Science.* Established in 1930 through the joint efforts of leading business firms and school authorities, and financed mainly by business subscribers, the Department of Business Administration

* The London School of Economics and Political Science (University of London), Houghton Street, Aldwych, W.C.2. Department of Business Administration, Session 1932-33. Pp. 28. Training for Business Management. Pp. 11. (London, 1932.) provides selected students with full-time training in the broad principles of business administration, as well as, where necessary, giving a preliminary general economic training. The Department does not aim at large numbers of students but at giving personal attention to a limited number each of whom has given evidence of an adequate general education and of personal qualities likely to make them suitable for a business career. The primary object of the training is to develop the quality of judgment and the breadth of view required for solving the practical problems which are encountered in business life. A secondary object is to provide a background against which the students can place the problems they afterwards meet.

With these objects in mind, instruction is carried on mainly by means of small discussion classes, including what is known as the problem or case method, supplemented by written work. Material supplied by business firms and illustrating the actual problems of business life is used in class discussions. In addition, the systematic investigation of business problems, organisation, and methods, mainly from the point of view of the individual concern, forms an integral part of the Department's work, and in time the Department hopes to cover a number of the major fields of business activity, although its present plans are limited to the study of certain aspects of marketing and business finance. In the latter field an investigation has been undertaken on the financial structure of business with the object of ascertaining whether normal forms of capitalisation exist for different types of business.

The Department of Business Administration is thus a definite attempt to meet the need for business training which is at present so ill provided for. Obvious criticisms can be made of its aims and methods, but it is not suggested that the course can do more than assist the formation and development of habits of judgment which will mature in actual experience of business and industrial life. The training provided by the Department has new advantages in the extent to which it renders available for the coming generation of administrators the experience of many firms of varying sizes and in different branches of industry or commerce. The breadth of experience thus offered is far greater than could be acquired in any one firm, apart from the practical difficulty which would be encountered in a firm of any size in the student acquiring experience by working his way through the different departments of the firm.

The scheme of training thus briefly outlined is an

No. 3275 , VoL. 130] 
experiment which is still developing and has not reached its final form. It can be justly claimed for this novel attempt to meet the need for fresh methods of recruiting and training business administrators for the future which arises from the changed economic conditions of the world, that it is based on a closer co-operation of academic and business authorities than has hitherto been achieved in Great Britain, and without abandoning any academic standard it seeks to base training for business upon business. It should not be too much to hope or expect that training along such lines will assist in the development not of scientific management as a restricted profession, however efficient, but in the provision for industry and the State alike of administrators versed in tried principles of administration and competent to assess the technical and scientific factors entering into problems they are called upon to solve. A generation of such administrators in government service and in industry would speedily ensure that the scientific expert took his rightful place in the business or mechanism of government in industry or in the State.

Inevitably, administrators of the required standard will only be forthcoming if the recruits for such courses are drawn as freely from scientific workers as from those who have graduated in arts or law or economics, and if the government service is at present lamentably behind industry in the scope it affords for administration by those having first-hand knowledge of science, the present tendency towards functional representation will ultimately make it easier for industry to influence State administration in the same direction. The firm establishment of the expert and the expert committee in industrial administration, and the proof of the scientific worker's competence to meet the searching demands of administration in an industrial merger on an international scale, should finally result in the scientific expert taking a corresponding part in the machinery of national and international government. Already the value of the expert committee has been demonstrated in the international sphere, and it behoves the scientific worker to watch with great interest all such experiments as that of the Department of Business Administration which seek to raise the standard of industrial administration or to promote scientific management, and to lose no opportunity of qualifying himself to discharge more efficiently those administrative functions from which in the present age he cannot escape, if industry and society alike are to avoid disintegration.

\section{Matter and Conceptions}

The New Conceptions of Matter. By Prof. C. G. Darwin. Pp. viii $+192+6$ plates. (London : G. Bell and Sons, Ltd., 1931.) 10s. $6 d$. net.

TN this book the author aspires to a popular 1 account of the recent developments of atomic physics-in particular, that aspect of it which is known as 'wave-mechanics'.

"I believe [he writes of his presentation] that it makes a consistent formulation of the foundations, which only needs the help of mathematics to yield all the results of the theory so far obtained. However that may be, I have little hesitation in saying that, if it is to be at all possible to present the new mechanics in popular or even semi-popular terms, it must be done more or less on the lines I have adopted here."

Speaking broadly, the method referred to may be described as that of giving a familiar physical interpretation to the mathematics of the subject. Since the mathematics does not on the whole lend itself to very obvious interpretation, this leaves considerable scope for the ingenuity of the expositor, and Prof. Darwin's chief difficulty has been to interpret the equations in the most ' natural' way.

"I shall count myself as having succeeded [he writes], if at the end of the book any surviving reader will speak no longer of the mysteries of science, but, shall we say, of the naturalness of Nature."

It may be said at once that, if we admit the legitimacy of the aim, the task could scarcely have been performed more satisfactorily, and many a student of advanced physics will call Prof. Darwin blessed. Every such student should read the book, for it provides him with what he will not obtain elsewhere with the same completeness and general excellence; namely, an approach to the incomprehensible mathematics of the subject by way of the physical counterparts of equations in more familiar branches of physics.

The account of the diffraction of electrons, the real starting-point of the book, is prefaced by some seventy pages of introductory matter dealing with fundamental physical conceptions, wave motion, and the principle of least action. As an interpretation of the new experimental facts we are introduced at once to the uncertainty principle and the duality of wave and particle, and in the light of these basic conceptions the structure and behaviour of the atom, polarisation of waves and particles, collisions between particles, and the exclusion principle are successively discussed. The

No. 3275, VoL. 130] 